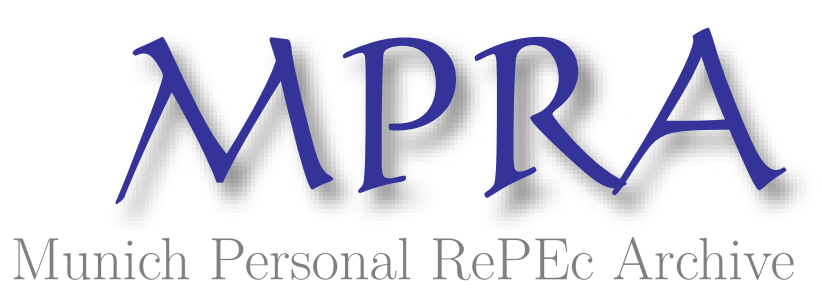

\title{
Consumer naivete and competitive add-on pricing on platforms
}

Ghosh, Meenakshi

Shiv Nadar University

1 October 2021

Online at https://mpra.ub.uni-muenchen.de/109981/

MPRA Paper No. 109981, posted 02 Oct 2021 13:27 UTC 


\title{
Consumer naïveté and Competitive Add-on Pricing on Platforms
}

\author{
Meenakshi Ghosh*
}

October 2021

\begin{abstract}
We model a situation where two sellers trade vertically and horizontally differentiated goods on a platform for which they are charged a commission fee. Sellers' costs are asymmetric due to differences in the fees charged by the platform and in their costs of production. Consumers purchase either a base good, or a bundle comprising of the base good and an add-on, from one of the sellers on the platform. Consumers differ in their brand preferences, valuations of quality and in their levels of sophistication. More specifically, we assume that there is a fraction of consumers who are naive, and do not observe or consider add-on prices - possibly because they do not foresee their demand for an add-on - until after they have committed to buying the base good from a seller. We examine how the interplay of these forces shapes consumer behaviour, sellers' pricing strategies and cost pass-through, and platform fees and revenues.

Keywords: add-on pricing, consumer naïveté, cost asymmetry, horizontal differentiation, platform fees, cost pass-through

JEL classification codes: L11, L15, L14, D43
\end{abstract}

*Email: meenakshi.ghosh@snu.edu.in; Address: Economics and Public Policy, School of Management and Entrepreneurship, Shiv Nadar University. 


\section{Introduction}

This paper is motivated by the observation that firms often shroud the prices of their addons - e.g. additional cover in insurance, printer toner cartridges, hotel mini bars, etc. from their consumers till the last stages of a transaction. To the extent that this precludes a comparison of the aggregate price of a good (inclusive of the add-on) across sellers, it may be to the detriment of consumers. Indeed, a market study by the Financial Conduct Authority (FCA) on general insurance add-ons in the UK concluded that the "... practice of revealing add-on prices only at the point of sale of the primary product is a very powerful barrier to consumers looking for alternatives...”. ${ }^{1}$ Similarly, a market investigation into private motor insurance by the Competition and Markets Authority (CMA) in the UK found that consumers were "... less likely to compare the price of add-ons from different providers once they had selected add-ons from their preferred provider of the basic [insurance] policy which [...] could lead to consumers paying higher prices for add-ons". 2 The Federal Trade Commission (FTC) too found in a study on auto sales and financing that "[f]or most consumers [...] add-ons did not come up until the financing process, if at all [...]. The limited amount of time and circumstances under which [they] had to consider add-on purchases, especially for consumers who were focused on buying a car and had not previously thought about buying add-ons, may have contributed to the lack of understanding and consumer confusion ..." ".

Alternatively, consumers may be unable to foresee their demand for add-ons, until after they have committed to purchasing the base good from a seller. This, again, results in purchasing decisions that are entirely based on prices of the base good alone, as the CMA found in its market investigation into retail banking in the UK: “... some overdraft customers may believe they do not need to shop around because they believe that they use their overdraft much less than they actually do or not at all. They may therefore not even think about searching for a product offering better overdraft charges and terms". ${ }^{4}$

Such consumer naïveté (in addition to differences in valuations of quality and brand preferences) takes on added relevance when sellers trade their goods on a platform and are

\footnotetext{
${ }^{1}$ Provisional Findings, General insurance add-ons market study, FCA, 2016, page 25.

${ }^{2}$ Final Report, Private Motor Insurance Market Investigation, CMA, 2014, para 7.45.

${ }^{3}$ Buckle Up: Navigating Auto Sales and Financing, Staff Report of the Bureau of Consumer Protection, FTC, 2020, page 9 .

${ }^{4}$ Final Report, Retail Banking Market Investigation, CMA, 2016, para 6.66.
} 
charged a commission fee that raises their costs. When there exist cost asymmetries between sellers - due to differences in the fees charged and/ or in marginal costs of production - and they pass on any increases in costs to their customers, it has a bearing on consumer choice, add-on pricing and cost pass-through, and platform fees and revenues.

More specifically, this paper examines the following research questions. First, how do sellers trading goods on a platform pass on the costs associated with commission fees to consumers, i.e. how do fees influence the price structure - the relative prices of base goods and add-ons - and the level of prices. How does the degree and nature of pass-through differ when sellers' marginal costs of production increase as opposed to an increase in their fees? Second, when a fraction of consumers are naive and are either uninformed about add-on prices or are unable to foresee their demand for the add-on at the outset, how does this influence cost pass-through? A related question is how does the naïveté of such consumers affect their welfare. Further, how does the fraction of consumers who only buy the base good affect pass-through? Third, how do cost asymmetries between sellers influence sellers' pricing strategies. Finally, how does the interplay of these forces affect the commission fees charged by the platform and its fees revenues? Are platforms benefitted by the presence of naive consumers who are captive at the point of sale and can be sold expensive add-ons? Or are their revenues increasing in the fraction of sophisticated, well informed consumers who drive down prices, thereby leading to greater buyer traffic on platforms? How do platforms determine the commission fees charged from sellers when some sellers enjoy cost efficiencies? Can fees potentially reverse the efficiencies enjoyed by a low-cost seller?

In our model, two sellers located at the ends of a Hotelling line sell vertically differentiated goods, namely a base good and a bundle of higher quality, comprising of the base good with an additional add-on. The sellers list their goods on a platform such as a price comparison web site which charges them a flat commission fee each time a sale is made via the platform. Fees are typically determined by the platform and are not ex ante identical across sellers. Further, marginal costs of production are identical for the two goods but vary across the sellers; we assume, without loss of generality, that seller 1's costs are higher.

Consumers, distributed uniformly along the Hotelling line, differ from one another in three dimensions. First, consumers are differentiated by an idiosyncratic taste parameter that captures how well the sellers' goods match their preferences. Second, they differ in 
their level of sophistication. We assume that naive consumers are, for the reasons mentioned above, entirely guided by the prices of base goods when choosing the seller to buy from, while sophisticated consumers take into account the total cost of the good (inclusive of the add-on) when choosing a seller. Finally, consumers differ in their marginal utility of income. As in Ellison (2005), consumers with lower marginal utilities of income have relatively higher incremental valuations of quality (are "high type") and are less sensitive to price differences across the sellers than consumers with a high marginal utility of income (are "low type"). We assume that of the high type consumers, a fraction are sophisticated while the rest are naive.

The timing of the game is as follows. First, the platform decides the commission fees to be paid by sellers. We capture the typically long-term and sticky nature of contracts between sellers and a platform and the continual entry of new sellers on the platform by modeling one of the sellers as an incumbent whose fees is determined by the platform at an earlier date. We assume, without loss of generality, that the high-cost seller is the incumbent and normalise its fees to one. Thus, the platform only determines the fees, $c_{2}^{*}$, to be paid by the efficient seller in the first stage. We assume that fees are common knowledge. Then, sellers simultaneously choose the prices of their base good and bundle. Finally, consumers decide whether to purchase the base good only or the bundle and the seller to buy from.

As expected, at the equilibrium, sellers charge a higher price for the bundle than for the base good alone and consumers self-select, with low type consumers buying only the base good and the high type consumers buying the add-on too. But, perhaps, the more interesting findings of the paper are to do with the impact of consumer naïveté, brand preferences and differences in valuations of quality, together with cost asymmetries between sellers, on sellers' pricing strategies and platform fees and revenues.

Lower costs allow the efficient seller to set a relatively low price for its base good, but interestingly, its add-on is more expensive than that sold by the high-cost seller. This is because a high priced add-on allows it to extract the relatively higher surplus of the naive consumers. Low headline prices lure these consumers (in addition to consumers with a low valuation of quality), who are then locked-in and sold expensive add-ons at the point of sale. In contrast, the high-cost seller passes on its higher costs through the price of its base good. As marginal costs of production are identical for the two goods, profit margins are higher on sales of the bundle. Consequently, the high-cost seller keeps its add-on prices low - in an attempt to keep 
the total price of its bundle competitive - so as to protect the more profitable sales of the bundle. Nevertheless, its bundle too is more expensive than the one sold by the efficient seller.

However, there are marked deviations from these pricing strategies when the fraction of low type consumers in the population is low enough, or when there are very few sophisticated or naive consumers in the population. Specifically, when there are no sophisticated consumers in the population, so that all consumers are either naive or are of low type, the relative prices of base goods become pivotal to purchase decisions. Consequently, competitive pressure ensures that base good prices converge. The high-cost seller is now unwilling to charge a high price of its base good and, instead, offers a more expensive add-on to recover its higher costs. Conversely, when there are no naive consumers, sellers have a lower incentive to set high prices for their add-ons (to extract the surplus of such consumers), and add-on prices converge. Lastly, when there are no low type consumers, the efficient seller offers a more expensive base good but lowers the price of its add-on. All consumers buy the bundle now and these price adjustments allow the efficient seller to charge a higher price for its bundle while maintaining the competitiveness of its price.

That the efficient seller's headlines prices are, in general, cheaper but its add-on more expensive, results, not surprisingly, in a mass of naive consumers who make suboptimal decisions; they purchase the bundle from the efficient seller and are ex post worse off than if they had purchased from the high-cost seller. We find that an increase in the commission fee, $c_{2}^{*}$, reduces the mass of such consumers by bringing about a realignment in the add-on prices of the sellers. Following an increase in the fee, the efficient seller raises the price of its base good partially to recover its higher costs (due to the increase), but reduces the price of its add-on to ensure that the price of its bundle remains competitive. In response, the prices of goods sold by the high-cost seller increase as well, but to a smaller extent. For similar reasons, an increase in the marginal cost of the sellers, that affects them both uniformly, is also passed on only through the price of the base good; however, in this case, the cost pass-through is complete.

The next set of findings examines how the extent of the cost pass-through (of higher fees) varies with changes in price sensitivities, the extent of consumer naïveté and differences in consumer valuations of quality. When the proportion of low type consumers in the population is very high, most consumers in the population are very price sensitive and purchase 
the base good only. Hence, the efficient seller is unable to pass on the increase in costs arising from an increase in fees through the price of the base good. As cost pass-through via the base good is low, the downward pressure on add-on prices (to keep bundle prices competitive) is also low. Consequently, add-on prices, too, decrease to a lesser extent. Similar results are obtained when the fraction of sophisticated consumers in the population, $\beta$, is high.

In the limiting case, i.e. when $\beta$ is close to zero, the prices of the sellers' base goods are equal, as discussed above, and any increase in fees results in an equal increase in these prices. In the absence of the relatively more price sensitive and sophisticated consumers, add-on prices have little bearing on the purchasing behaviour of consumers; the low type consumers buy only the base good while the naive consumers do not consider these prices at the outset and are captive at the point of sale. Thus, the efficient seller passes on the increase in costs (arising from an increase in fees) by selling more expensive add-ons than before.

Conversely, when $\beta$ is close to one, there are no naive consumers and sellers lose the incentive to set high prices for their add-ons. The efficient seller passes on an increase in its costs by charging a higher price for its base good. Add-on prices are left unchanged to keep the total price of its bundle competitive.

The last set of findings examines platform fees and revenues. We find that the platform charges a higher fee from the efficient seller but this higher rate does not reverse the latter' cost advantage. This is because when $c_{2}^{*}>1$, a further increase in fees, at the equilibrium, results in a loss in net fee revenue - due to shifts in demand in favour of the high-cost seller following changes in relative prices as discussed above - that is exactly offset by the gain in revenue due to the higher fee, per se. Simply put, the higher fee allows the platform to gain greater fee revenues by leveraging the higher demand that the efficient seller faces due to its cost efficiencies.

Further, we find, perhaps counterintuitively, that platform revenues are increasing in the price sensitivity of naive consumers. When consumers are more price sensitive, lower prices charged by the efficient seller, at equilibrium, result in a greater demand for its goods. This, in turn, results in an increase in the platform's fees revenues as it charges a higher fee from the efficient seller. However, heightened price sensitivity also results in a lower fee (which, in turn, influences prices and demand), but we find that the former effect dominates so that revenues increase. 
Also, one may expect that as low type consumers buy only the low priced base good, an increase in the proportion of such consumers in the population would depress the platform's revenues. We find that the converse holds true and that revenues increase. This is because while $c_{2}^{*}$ decreases with an increase in the proportion of such consumers - leading to a drop in the platform's revenues - there is also a shift in demand in favour of the efficient seller. The latter occurs due to a change in relative prices following an increase in the proportion of low type consumers - base good prices fall for both sellers, with a greater drop observed in the prices of goods sold by the efficient seller (due to its lower costs). As $c_{2}^{*}>1$, this shift in demand results in an increase in platform fees revenues. We find that the latter effect dominates.

Again, contrary to the expectation that an increase in the fraction of sophisticated consumers in the population would depress platform revenues - owing to their greater price sensitivity and sophistication - revenues increase. An increase in the presence of such consumers in the population results in a site-wide drop in prices (including that of the add-on), with a disproportionately greater drop in prices of goods sold by the efficient seller. This shifts demand in favour of the efficient seller and as it is charged a higher fee, platform revenues increase. We find that the fee itself, decreases too, but the former effect dominates leading to an increase in revenues.

Finally, revenues are found to be increasing in the cost advantage of the efficient seller. An increase in the latter results in lower costs leading to a drop in prices charged by the efficient seller. In response, the high-cost seller lowers its prices too, though to a lesser extent, leading to a shift in demand in favour of the efficient seller. As the fees charged from the latter are higher, platform revenues increase. Further, $c_{2}^{*}$ itself rises with increases in the cost advantage, so that revenues increase.

Related Literature: This paper is at the interface of three streams of literature. The first examines add-on pricing strategies of firms; more specifically, the factors influencing a firm's decision to bundle add-ons, their pricing and the impact on profits. While early studies (Gabaix and Laibson (2006), Lal and Matutes (1994), Verboven (1999)) argued that any profits earned on add-ons would be competed away in the form of lower prices of the base good, Ellison (2005) was the first to show that add-ons can actually raise profits by creating an adverse selection problem that makes price-cutting unappealing. Other studies 
focus on factors that impinge on a firm's decision of whether to bundle add-ons, and their pricing. For instance, Geng et al. (2018) explores how a firm's add-on strategy is influenced by an online platform's distribution contract choice. Similarly, Choudhary and Zhang (2016) analyses the impact of competition on firms' decisions of whether to bundle add-ons or offer them à la carte, when firms have asymmetric qualities. Borenstein et al. (2000) looks at whether competition in the durable-equipment market necessarily suppresses the exercise of market power in the aftermarket.

The second stream of literature studies how consumer naïveté affects market outcomes. Shapiro (1995) identifies the presence of myopic/ poorly informed consumers as one of the causes of market failure in aftermarkets. Verboven (1999) studies firms' add-on pricing strategies in an environment with vertical and horizontal differentiation, where there is a group of myopic consumers in the market. Gabaix and Laibson (2006) examines firms' decisions of whether to advertise or shroud their add-on prices when some consumers are boundedly rational or myopic and derives conditions under which competitive price cutting and educational advertising does not occur in equilibrium.

Armstrong (2015) discusses when the presence of savvy consumers results in search externalities that improve the deals available to all consumers, and when non-savvy consumers give rise to ripoff externalities and fund generous deals for all consumers. Shulman and Geng $(2013,2016)$ examine the implications for consumer welfare and profits when firms are horizontally and vertically differentiated and there is a segment of naive consumers who are unaware of add-on fees at the outset.

More recently, an emerging stream of literature focuses on agency pricing and examines how involvement of trading platforms and the nature of the contract between them and firms influences pricing strategies. Hao and Fan (2014) studies pricing of e-books and e-readers and social welfare under wholesale and agency pricing models. Ronayne (2020) examines whether consumers, including those who do not use price comparison websites, are better off with the presence of such sites in the market place. Wang and Wright (2020) argues that despite the possibility of showrooming, insistence on price parity clauses such as MFNs often harm consumers. Other work in this area includes Tian et al. (2017) that examines profitability under wholesale pricing vs. agency pricing. Similarly, Hao et al. (2016) examines advertising revenue-sharing contracts under agency pricing for app sales. 
This paper adds to the literature by examining how naïveté, brand preferences and differing price sensitivities of consumers, together with cost asymmetries between sellers, influence consumer buying behaviour, pricing strategies and cost pass-through by sellers and platform revenues. More specifically, it explores the level and the structure of prices - i.e. the relative prices of base goods and add-ons - and the extent of cost pass-through, when sellers are charged a commission fee for trading their goods on a platform which, in turn, is shaped by the interplay of these factors.

The rest of the paper is structured as follows. The next section lays out the model while Section 3 describes the key findings of the paper. Section 4 concludes the paper. Proofs are collected in an Appendix.

\section{Model}

There are two sellers in the market, indexed by $i \in\{1,2\}$ and located at the two ends of a Hotelling line, that sell two vertically differentiated goods. These include a base good of low quality and a bundle of higher quality, comprising of the base good with an additional add-on, with prices $p_{i L}$ and $p_{i H}$ respectively. Marginal costs of production are constant and identical for the low and high quality goods, but vary across the sellers. We assume, without loss of generality, that seller 1's marginal cost is $k$ while seller 2's cost is $k-x$, where $x>0$.

Sellers list their goods on a platform such as a price comparison web site, which charges a flat commission fee each time a sale is made via the platform. We assume that fees are determined by the platform and are not ex ante identical across sellers. As new sellers continually enter the market and negotiate with platforms to appear in their listings, and contracts between platforms and sellers are typically long term and sticky in nature, we model a situation whereby there is an incumbent seller with an existing contract. Without loss of generality, we normalise the commission fees paid by this seller to one, i.e. $c_{1}=1$, while the fees paid by a new seller, $c_{2}$, is determined by the platform so as to maximise its payoff.

There is a measure one of consumers, distributed along the Hotelling line, who differ from one another in three dimensions. First, consumers are differentiated by an idiosyncratic taste parameter $\theta \sim U[0,1]$ that characterises how well the sellers' goods match their preferences. Second, consumers differ in their level of sophistication. More specifically, some 
consumers are naive and either cannot observe or do not consider sellers' add on prices possibly because they do not foresee their demand for the add-on - until after they have committed to purchasing the base good from a seller. Therefore, such consumers only consider the price of the base good when choosing which seller to buy from. However, they are locked-in and buy high-priced add-ons at the point of sale. In contrast, sophisticated consumers consider the aggregate price of a good, i.e. inclusive of the add-on, when choosing a seller. Finally, consumers differ in their marginal utility of income, $\alpha$. Thus, for a proportion $\gamma$ of consumers, $\alpha=\alpha_{l}$. Of the remaining $1-\gamma$ consumers, for a proportion $\beta$ of consumers, $\alpha=\alpha_{s}$, while for the remaining $(1-\gamma)(1-\beta)$ consumers, $\alpha=\alpha_{n}$, where $0<\alpha_{n}<\alpha_{s}<\alpha_{l}$. As in Ellison (2005), consumers with lower marginal utilities of income, i.e. $\alpha=\alpha_{s}$, $\alpha_{n}$, have a relatively higher incremental valuation of quality (are "high type") and are less sensitive to price differences across the sellers than consumers with $\alpha=\alpha_{l}$ (are "low type"). We assume that consumers with $\alpha=\alpha_{s}$ are sophisticated, while those with $\alpha=\alpha_{n}$ are naive. Indeed, the CMA found that "... customers [who] use an unarranged overdraft facility are generally less likely to switch than [those using] an arranged overdraft facility". ${ }^{5,6}$

The utility of a consumer of type $(\theta, \alpha)$ from consumption of the high quality bundle is $u-\theta-\alpha p_{1 H}$ when he buys from the high-cost seller and $u-(1-\theta)-\alpha p_{2 H}$ if he buys from the efficient seller. His utility, $u-y-\theta-\alpha p_{1 L}, y>0$, is lower, if he buys the base good from the high-cost seller and $u-y-(1-\theta)-\alpha p_{2 L}$ if he buys it from the efficient seller. Each consumer buys at most one unit of the good and derives zero utility if he does not make a purchase. We assume that $u$ is large enough so that the market is covered.

The timing of the game is as follows. First, the platform decides the commission fees, $c_{2}^{*}$, to be paid by the efficient seller (with $c_{1}^{*}$ normalised to one); fees are common knowledge. Second, sellers simultaneously choose the prices of their goods, $p_{i L}$ and $p_{i H}, i \in\{1,2\}$. Finally, consumers decide whether to purchase the base good only or the high quality bundle and the seller to buy from. Note that the add-on cannot be bought in isolation.

\footnotetext{
${ }^{5}$ Final Report, Retail Banking Market Investigation, CMA, UK, 2016, para 6.46.

${ }^{6}$ Overdraft facilities refer to the ability to borrow money from a bank on a short-term flexible basis, whether arranged in advance with the bank or unarranged.
} 


\section{Equilibrium}

As "high type" consumers (with $\alpha=\alpha_{s}, \alpha_{n}$ ) have a higher valuation of quality, they are more likely to buy add-ons while "low type" consumers (with $\alpha=\alpha_{l}$ ) buy the base good only. For such purchasing behavior to hold, the following individual rationality and incentive compatibility constraints must be satisfied.

i. For low type consumers who buy the base good from, say, the high-cost seller:

$$
\begin{aligned}
u-y-\theta-\alpha_{l} p_{1 L} & \geq 0 \\
u-y-\theta-\alpha_{l} p_{1 L} & \geq u-\theta-\alpha_{l} p_{1 H} \\
u-y-\theta-\alpha_{l} p_{1 L} & \geq u-(1-\theta)-\alpha_{l} p_{2 H} \\
u-y-\theta-\alpha_{l} p_{1 L} & \geq u-y-(1-\theta)-\alpha_{l} p_{2 L}
\end{aligned}
$$

ii. For high type sophisticated consumers who buy the bundle from, say, the high-cost seller:

$$
\begin{aligned}
& u-\theta-\alpha_{s} p_{1 H} \geq 0 \\
& u-\theta-\alpha_{s} p_{1 H} \geq u-y-\theta-\alpha_{s} p_{1 L} \\
& u-\theta-\alpha_{s} p_{1 H} \geq u-y-(1-\theta)-\alpha_{s} p_{2 L} \\
& u-\theta-\alpha_{s} p_{1 H} \geq u-(1-\theta)-\alpha_{s} p_{2 H}
\end{aligned}
$$

iii. For high type naive consumers who choose a seller based on a comparison of base good prices but eventually buy the bundle from, say, the high-cost seller:

$$
\begin{aligned}
u-\theta-\alpha_{n} p_{1 H} & \geq 0 \\
u-\theta-\alpha_{n} p_{1 H} & \geq u-y-\theta-\alpha_{n} p_{1 L} \\
u-y-\theta-\alpha_{n} p_{1 L} & \geq u-y-(1-\theta)-\alpha_{n} p_{2 L}
\end{aligned}
$$

Similar constraints apply for consumers who purchase from the other seller.

We first consider the demand from low type consumers. Such consumers are indifferent 
between the two sellers if

$$
u-y-\theta-\alpha_{l} p_{1 L}=u-y-(1-\theta)-\alpha_{l} p_{2 L}
$$

The high-cost seller draws consumers with

$$
\theta \leq \theta_{l}=\frac{1}{2}+\frac{\alpha_{l}\left(p_{2 L}-p_{1 L}\right)}{2}
$$

while the remaining consumers buy from the other seller. The high-cost seller's profit from such consumers is then given by

$$
\gamma\left(\frac{1}{2}+\frac{\alpha_{l}\left(p_{2 L}-p_{1 L}\right)}{2}\right)\left(p_{1 L}-1-k\right)
$$

Next, we consider the demand from sophisticated consumers who purchase the add-on as well and take its price into consideration at the time of making their purchase decision. Specifically, they compare the total price of the good across sellers when deciding who to purchase from. Such consumers are indifferent between the two sellers if

$$
u-\theta-\alpha_{s} p_{1 H}=u-(1-\theta)-\alpha_{s} p_{2 H}
$$

They buy from the high-cost seller if

$$
\theta \leq \theta_{s}=\frac{1}{2}+\frac{\alpha_{s}\left(p_{2 H}-p_{1 H}\right)}{2}
$$

while the remaining consumers buy from the other seller. Then, the high-cost seller's profit from such consumers is given by

$$
(1-\gamma) \beta\left(\frac{1}{2}+\frac{\alpha_{s}\left(p_{2 H}-p_{1 H}\right)}{2}\right)\left(p_{1 H}-1-k\right)
$$

Finally, we consider the demand from naive consumers. They are indifferent between the two sellers if

$$
u-y-\theta-\alpha_{n} p_{1 L}=u-y-(1-\theta)-\alpha_{n} p_{2 L}
$$


and buy from the high-cost seller if

$$
\theta \leq \theta_{n}=\frac{1}{2}+\frac{\alpha_{n}\left(p_{2 L}-p_{1 L}\right)}{2}
$$

However, since they eventually buy the add-on too, the high-cost seller's profit from such consumers is

$$
(1-\gamma)(1-\beta)\left(\frac{1}{2}+\frac{\alpha_{n}\left(p_{2 L}-p_{1 L}\right)}{2}\right)\left(p_{1 H}-1-k\right)
$$

Note that naive consumers, owing to their naïveté or lack of information, may not, ex post, always make rational choices. In particular, as their choice of seller is entirely guided by a comparison of the prices of base goods but they purchase the add-on too at the point of sale, it may be that some consumers would be better off purchasing the bundle from the other seller.

Then, from equations (1), (2) and (3), the high-cost seller's maximisation problem is

$$
\begin{aligned}
& \max _{p_{1 L}, p_{1 H}} \pi_{1}=\gamma\left(\frac{1}{2}+\frac{\alpha_{l}\left(p_{2 L}-p_{1 L}\right)}{2}\right)\left(p_{1 L}-1-k\right)+ \\
&(1-\gamma) \beta\left(\frac{1}{2}+\frac{\alpha_{s}\left(p_{2 H}-p_{1 H}\right)}{2}\right)\left(p_{1 H}-1-k\right)+ \\
&(1-\gamma)(1-\beta)\left(\frac{1}{2}+\frac{\alpha_{n}\left(p_{2 L}-p_{1 L}\right)}{2}\right)\left(p_{1 H}-1-k\right)
\end{aligned}
$$

Similarly, the low-cost seller's maximisation problem is

$$
\begin{aligned}
\max _{p_{2 L}, p_{2 H}} \pi_{2}=\gamma\left(\frac{1}{2}-\frac{\alpha_{l}\left(p_{2 L}-p_{1 L}\right)}{2}\right)\left(p_{2 L}-c_{2}-k+x\right)+ \\
(1-\gamma) \beta\left(\frac{1}{2}-\frac{\alpha_{s}\left(p_{2 H}-p_{1 H}\right)}{2}\right)\left(p_{2 H}-c_{2}-k+x\right)+ \\
\quad(1-\gamma)(1-\beta)\left(\frac{1}{2}-\frac{\alpha_{n}\left(p_{2 L}-p_{1 L}\right)}{2}\right)\left(p_{2 H}-c_{2}-k+x\right)
\end{aligned}
$$

Suppose the prices that maximise sellers' profits are $p_{1 L}^{*}\left(c_{2}\right), p_{2 L}^{*}\left(c_{2}\right), p_{1 H}^{*}\left(c_{2}\right)$ and $p_{2 H}^{*}\left(c_{2}\right)$. Then, the platform's payoff, comprising of the revenues from the commission fee it charges 
the sellers, is given by

$$
\begin{aligned}
\pi_{P}=\gamma\left(\frac{1}{2}+\frac{\alpha_{l}\left(p_{2 L}^{*}-p_{1 L}^{*}\right)}{2}\right)+(1-\gamma) \beta\left(\frac{1}{2}+\frac{\alpha_{s}\left(p_{2 H}^{*}-p_{1 H}^{*}\right)}{2}\right)+ \\
(1-\gamma)(1-\beta)\left(\frac{1}{2}+\frac{\alpha_{n}\left(p_{2 L}^{*}-p_{1 L}^{*}\right)}{2}\right)+c_{2} \gamma\left(\frac{1}{2}-\frac{\alpha_{l}\left(p_{2 L}^{*}-p_{1 L}^{*}\right)}{2}\right)+ \\
c_{2}(1-\gamma) \beta\left(\frac{1}{2}-\frac{\alpha_{s}\left(p_{2 H}^{*}-p_{1 H}^{*}\right)}{2}\right)+c_{2}(1-\gamma)(1-\beta)\left(\frac{1}{2}-\frac{\alpha_{n}\left(p_{2 L}^{*}-p_{1 L}^{*}\right)}{2}\right)
\end{aligned}
$$

and the platform maximises its payoff with respect to the commission fees, $c_{2}$.

We find that, as expected, sellers charge a higher price for the bundle than for the base good, at the equilibrium, and consumers self-select, with low type consumers buying only the base good and the high type consumers buying the add-on too. Lower total costs, despite higher fees, allow the efficient seller to keep its prices low - its base good and bundle prices are cheaper but its add-on is more expensive. Due to its low headline and bundle prices it draws a greater share of the low type and sophisticated consumers. In addition, a greater number of naive consumers - who are entirely guided by relative prices of base goods in their choice of seller - also opt to purchase from the efficient seller. Once locked-in, they are sold expensive add-ons that allow the efficient seller to extract their relatively higher surplus. In contrast, the high-cost seller passes on its higher costs through the price of its base good. Sales of the bundle are more profitable - as the marginal costs of producing the base good or the bundle are identical - and the high-cost seller keeps its add-on prices low in an attempt to keep the total price of its bundle competitive. Nevertheless, its bundle is more expensive than the one sold by the efficient seller.

Consequently, there is a mass of naive consumers (bounded above by $\frac{1}{2}$ ), who ex post, make a sub-optimal decision in purchasing the bundle from the efficient seller; more specifically, their payoff would have been higher had they purchased, instead, from the high-cost seller.

Interestingly, this mass of naive consumers is decreasing in commission fees, $c_{2}^{*}$. This is because an increase in the latter lowers the price of the efficient seller's add-on and raises the price of the add-on sold by the high-cost seller, in addition to raising the prices of both base goods. This realignment in prices occurs for the following reason. An increase in fees, $c_{2}^{*}$, raises the efficient seller's costs, that it attempts to recover by passing on to consumers. 
Since, sales of the bundle are more profitable owing to their greater margins, the seller passes on an increase in costs primarily through the price of its base good. At the same time, it reduces the price of its add-on, so that the total price of its bundle remains competitive. In response, and given that all consumers are served, the high-cost seller raises its prices too, though to a smaller extent.

We also find that base good prices are decreasing in the fraction of low type consumers, with a greater drop observed in the price charged by the efficient seller, due to its lower costs. There is no change in the prices of add-ons. Similarly, an increase in the mass of sophisticated consumers exerts a downward pressure on all prices due to their greater price sensitivity and consideration of the total price of the bundle in all purchasing decisions.

The following proposition summarises these findings.

Theorem 1 (Equilibrium). Suppose two sellers list their vertically and horizontally differentiated products on a platform for which they pay the latter a commission fee. Then, for $\alpha_{s}, \alpha_{l}$ high enough, there exists an equilibrium such that for $y \in[\underline{y}, \bar{y}]$ and $u \geq \underline{u}$, where $\underline{y}, \bar{y}, \underline{u}>0$, at the equilibrium,

i. Low type consumers with a high marginal utility of income, $\alpha_{l}$, buy only the base good while the high type consumers with lower marginal utilities of income, $\alpha_{s}$ or $\alpha_{n}$, purchase the add-on too.

ii. There is a mass of naive consumers, decreasing in the commission fees charged from the efficient seller, who buy the high quality bundle from the efficient seller but who would have been better off buying from the high-cost seller instead.

iii. When $\alpha_{n}$ is low enough, prices of base goods sold by both sellers are decreasing in $\gamma$, with a greater drop observed in the price of the good sold by the efficient seller. There is no change in the prices of add-ons.

$i v$. When $\alpha_{n}$ is low enough, prices of base goods are decreasing in $\beta$, with a greater drop observed in the price of good sold by the efficient seller. Prices of add-ons decrease as well.

The next proposition describes the sellers' pricing strategies.

Theorem 2 (Pricing Strategies). When $\alpha_{l}, \alpha_{s}$ are high enough, 
i. The high-cost seller offers a more expensive base good than the efficient seller; however, the reverse holds when the proportion of low type consumers, $\gamma$, is low enough. Prices of base goods are equal across sellers when there are very few sophisticated consumers in the population.

ii. The high-cost seller offers a cheaper add-on than the efficient seller; however, the reverse holds when the proportion of low type consumers, $\gamma$, is low enough, or when there are very few sophisticated consumers in the population. Prices of add-ons are equal across sellers when there are very few naive consumers.

As discussed above, the efficient seller's base good and bundle are cheaper but its add-on is more expensive. When $\beta$ is close to zero, consumers are either naive or have a very low valuation of quality. For such consumers, it is only the relative prices of base goods that matter, as their purchase decisions, including the choice of seller, are entirely based on a comparison of these prices alone. Consequently, competitive pressure between sellers ensures that prices of their base goods are equal so that, at the equilibrium, exactly half of the mass of consumers purchases from either seller. As the high-cost seller is now unwilling to set too high a price for its base good, it offers a more expensive add-on, reflecting its higher cost.

On the other hand, when $\beta$ is close to one and there are no naive consumers, sellers have a lower incentive to set a high price for their add-ons. This is because there are no captive consumers who can be sold expensive add-ons; rather, all consumers are relatively more price sensitive and factor in the full cost of the products they intend to buy, at the outset. Then, prices of add-ons sold by the two sellers are equal and the price of the base good sold by the high-cost seller is higher, as before, owing to its higher costs.

Finally, when $\gamma$ is close to zero, all consumers purchase the high quality bundle. The efficient seller's base good is now more expensive and its add-on cheaper. This is because the efficient seller now has a lower incentive to set low base good prices; there are no low type consumers who buy the base good only, and the naive consumers - though influenced by a comparison of base good prices - are relatively price insensitive. Instead, it reduces the price of its add-on; this rearrangement in prices allows it to charge a higher price for its bundle, but at the same time, maintain the competitiveness of its price, i.e. $p_{1 H}^{*}>p_{2 H}^{*}$.

The proposition below explores how the degree of pass-through - whether of increases 
in fees or marginal costs of production - depends on factors such as the price sensitivity of naive consumers, extent of naïveté among consumers and their valuations of quality.

Theorem 3 (Cost pass though). When $\alpha_{s}, \alpha_{l}$ are high enough,

a. Increases in commission fees, $c_{2}^{*}$, result in

i. an increase in prices of base goods and the add-on sold by the high-cost seller and a decrease in the price of the add-on sold by the efficient seller. Cost pass-through is incomplete, i.e. the entire increase in fees is not passed on to consumers.

ii. a smaller increase in the price of the base good and a smaller decrease in the price of the add-on sold by the efficient seller with increases in the mass of sophisticated consumers or low type consumers.

iii. an increase in the price of the base good and the add-on of the efficient seller when there are no sophisticated consumers, i.e. $\beta=0$.

$i v$. an increase in the price of the base good sold by the efficient seller, with no changes in the price of its add-on, when there are no naive consumers, i.e. $\beta=1$.

b. Increases in marginal costs of production, $k$, that uniformly affect the sellers, are completely passed on by sellers in the form of higher prices of base goods.

That an increase in commission fees charged from the efficient seller leads to a rise in base good prices and the price of the add-on sold by the high-cost seller but a drop in add-on prices of the efficient seller has been discussed above. We also find that while the pass-through of higher fees is incomplete, increases in marginal costs, $k$, that uniformly affect both sellers are entirely passed on to consumers, through higher prices of the base good, i.e. $\frac{\delta p_{i L}}{\delta k}=1, i \in 1,2$.

Next, when $\gamma$ is high, so that there are more low type consumers who buy only the base good, the efficient seller is unable to pass on an increase in fees through a higher price of its base good. As cost pass-through via the base good is low, the downward pressure on add-on prices (to keep bundle prices competitive) is also low. Consequently, add-on prices, decrease to a lesser extent. Similar results are obtained when $\beta$, the fraction of the price sensitive sophisticated consumers in the population, is high. 
Recall from Theorem 2 that when $\beta$ is close to zero so that all high type consumers are naive, competitive pressure between sellers ensures that the prices of their base goods are equal and any increases in the fees charged from the efficient seller result in an equal increase in these prices. In the absence of the relatively more price sensitive and sophisticated consumers, add-on prices have little bearing on the purchasing behaviour of consumers; the low type consumers buy only the base good while the naive consumers do not consider these prices at the outset and are captive at the point of sale. Thus, the efficient seller passes on the increase in its costs (arising from the higher fee) by selling more expensive add-ons too, than before.

Conversely, when $\beta$ is close to one and there are no naive consumers, sellers have a lower incentive to set high prices for their add-ons. The efficient seller passes on an increase in its costs by charging a higher price for its base good. Add-on prices are left unchanged by both sellers to keep the total price of the bundle competitive.

The final proposition of the paper examines how the interplay of cost asymmetries and differences in valuations of quality and the level of sophistication influences platform fees and revenues. First, we find that the platform charges a higher commission fee from the efficient seller. This is because when $c_{2}^{*}>1$, a further increase in fees, at the equilibrium, results in a loss in net fee revenue (due to a shift in demand across sellers following changes in relative prices, as discussed above) that is exactly matched by the gain in revenue due to the higher fee/ rate, per se. Nevertheless, we find that this does not reverse the cost advantage of the efficient seller, i.e. $1+x-c_{2}^{*}>0$.

Next, as $\alpha_{n}$ increases, platform revenues increase. This is because an increase in the price sensitivity of naive consumers has two effects. First, as prices of the goods sold by the efficient seller are lower at equilibrium, an increase in $\alpha_{n}$ implies a greater shift in demand (of the naive consumers) from the high-cost seller to the efficient seller. These shifts in demand across sellers result, in turn, in an increase in fees revenues for the platform as it charges a higher fee from the efficient seller. Second, an increase in price sensitivity also results in a drop in fee revenues due to a decline in the fee, $c_{2}^{*}$, charged from the efficient seller, per se, as discussed below. Incidentally, this decrease in fees, in turn, also changes relative prices in favor of the efficient seller, leading to an increase in the demand faced by it, and reinforces the first effect. We find that, at the equilibrium, the first effect outweighs the second effect, 
resulting in an increase in total revenues of the platform.

That an increase in $\alpha_{n}$ results in a lower fee charged from the efficient seller may be explained as follows. Recall that at the equilibrium, $c_{2}^{*}$ is so chosen that:

$$
\frac{\delta \pi_{P}}{\delta c_{2}}=\frac{\delta D_{1}}{\delta c_{2}}+c_{2}^{*} \frac{\delta D_{2}}{\delta c_{2}}+D_{2}=0
$$

where $D_{1}, D_{2}$ are the demands faced by high-cost and efficient seller respectively. Since the market is covered, $\frac{\delta D_{1}}{\delta c_{2}^{*}}=-\frac{\delta D_{2}}{\delta c_{2}^{*}}$, so that,

$$
\frac{\delta \pi_{P}}{\delta c_{2}}=\left(c_{2}^{*}-1\right) \frac{\delta D_{2}}{\delta c_{2}}+D_{2}=0
$$

As discussed earlier, an increase in the fees/ rate, per se, raises the revenues received from the efficient seller (second term in the expression above). But, in addition, it also leads to a shift in demand away from the efficient seller, i.e. $\frac{\delta D_{2}}{\delta c_{2}}<0$, because a higher fee adds to its total costs of production and is passed on to consumers in the form of higher prices. The high-cost seller effects an increase in his prices too, in response, but to a lesser extent. This shift in demand, in turn, causes a drop in the net fees revenues obtained from the two sellers as $c_{2}^{*}>1$ (first term in (7)). A high $\alpha_{n}$ reinforces both these effects; demand faced by the efficient seller, whose products are cheaper, is higher when naive consumers are more price sensitive (second term in (7)). But, with a high $\alpha_{n}$, demand faced by the efficient (high-cost) seller also decreases (increases) to a greater extent with increases in fees - partly due to the heightened price sensitivity of naive consumers - resulting in a greater drop in revenues from fees (first term in (7)). We find that the latter effect dominates, leading to a lower commission fee than when $\alpha_{n}$ is low.

Platform revenues are also increasing in the proportion of sophisticated consumers in the population, $\beta$. As discussed earlier, an increase in the number of such consumers exerts a downward pressure on the price of add-ons and base goods, with a greater drop in the price of goods sold by the efficient seller. Consequently, relative prices change in favour of the efficient seller, resulting in a shift of demand to the latter and an increase in the net fees revenues received from the two sellers (as $c_{2}^{*}>1$ ). However, $c_{2}^{*}$ itself is decreasing in $\beta$ resulting in a drop in revenues. We find that the first effect dominates leading to an increase in revenues.

The fees, $c_{2}^{*}$, itself is decreasing in $\beta$ as an increase in the fraction of sophisticated con- 
sumers in the population leads to a greater drop in prices of the efficient seller and increases the demand faced by it (second term in (7)). However, it also results in a greater shift in demand away from the efficient seller - as there are more sophisticated consumers now who make this switch - when increases in fees make its bundle relatively more expensive than before (first term in (7)). We find that the latter effect dominates so that fees decrease.

Similarly, we find that fees are decreasing in $\gamma$. As the fraction of low type consumers in the population increases, base good prices fall, with a greater drop observed in the case of the efficient seller. This leads to an increase in demand faced by the efficient seller (second term in (7)). However, with increase in fees, demand also shifts away from the efficient seller due to an increase in the prices of its goods, due to cost pass-through. When $\gamma$ is high, this shift in demand occurs to a greater extent as there are more low type consumers (first term in (7)) who make this shift. We find that the second effect dominates so that fees are decreasing in $\gamma$. This, drop in fees, per se, has the effect of reducing the platform's revenues. However, an increase in $\gamma$ also leads to an increase in revenues - by bringing about a greater drop in the price of the base good sold by the efficient seller, it shifts demand in favor of the efficient seller. As the fees charged from the latter is higher, this leads to an increase in revenues. We find that, at the equilibrium, the latter effect dominates, so that revenues are increasing in $\gamma$.

Finally, revenues are increasing in the efficient seller's cost advantage, $x$. As $x$ increases, its total costs, and hence, prices fall. The high-cost seller lowers its prices too, in response, though to a lesser extent. Following this change in relative prices, demand shifts in favour of the efficient seller, and consequently, net fees revenues increase. But, $c_{2}^{*}$ itself is increasing in $x$ as well, so that total revenues increase. Fees are increasing in $x$ because neither the extent of the cost advantage, $x$, nor, in fact, the marginal cost of production, $k$, has any impact on the degree of pass-through (first term in (7)). Rather, it is only the demand faced by sellers that is affected - an increase in the cost advantage leads to a further drop in prices of the efficient seller due to which it draws a greater number of consumers than before (second term in (7)). Hence, from (7), a higher $x$ is associated with a higher fee.

The following proposition summarises these findings.

Theorem 4 (Platform Revenues and Fees). When $\alpha_{l}, \alpha_{s}$ are high enough,

i. The platform charges a higher commission fee from the efficient seller; however, this 
does not reverse the cost advantage of the efficient seller, i.e. $1+x-c_{2}^{*}>0$.

ii. The platform's fee revenues are increasing in the proportion of sophisticated consumers in the population (when $\alpha_{n}$ is low enough as well), the proportion of low type consumers (when $\alpha_{n}$ is low enough as well), the marginal utility of income of the naive consumers and the extent of the cost advantage of the efficient seller.

iii. The commission fees charged from the efficient seller is increasing in the extent of the cost advantage of the efficient seller and decreasing in the proportion of sophisticated consumers in the population (when $\alpha_{n}$ is low enough as well), the proportion of low type consumers (when $\alpha_{n}$ is low enough as well) and the marginal utility of income of the naive consumers.

\section{Conclusion}

There is a vast literature that focuses on add-on pricing strategies of firms, involving the factors that influence firms' decisions of whether to bundle add-ons, their pricing and profits. Other streams of literature examine the impact of consumer naïveté on market outcomes, and agency pricing, i.e. how the involvement of trading platforms and the nature of contracts between platforms and firms influence pricing strategies. What has received less attention is how consumer choice, add on pricing - and the related issue of cost pass-through - and platform fees and revenues are influenced by consumer naïveté, differences in valuation of quality and cost asymmetry between firms when sellers are charged a fee for trading their goods on a platform. This paper attempts to fill this gap in the literature.

We find that there exists an equilibrium where consumers with a high marginal utility of income buy the base good while consumers with relatively lower marginal utilities of income buy the high quality bundle. Lower costs permit the efficient seller to charge low headline prices and high add-on prices. This allows them to lure the price insensitive, naive consumers who are then locked-in and sold expensive add-ons at the point of sale. Not surprisingly, this results in a mass of consumers who are ex post worse off buying the bundle from the efficient seller; they would have been better off purchasing from the high-cost seller instead. However, we find that there are marked deviations from this pricing strategy when the fraction of low 
type consumers in the population is low, or when there are very few sophisticated, or naive consumers in the population. This paper also examines how the degree of cost pass-through - of increases in marginal costs of production and commission fees - depends on the interplay of these factors.

Finally, we examine platform fees and revenues; we find that the platform charges a higher fee from the efficient seller. Further, its revenues are increasing in the fraction of sophisticated and low type consumers in the population, the price sensitivity of the naive consumers and the extent of the cost advantage of the efficient seller. The fees charged from the efficient seller, however, is increasing in the extent of the cost advantage of the efficient seller only but decreasing in the other parameters. 


\section{References}

Armstrong, M. (2015), "Search and Ripoff Externalities", Review of Industrial Organisation, Issue 47, 273 - 302.

Borenstein, S., J. K. Mackie-Mason and J. S. Netz (2000), "Exercising Market Power in Proprietary Aftermarkets", Journal of Economics and Management Strategy, IX, $157-188$.

Choudhary, V. and R.Zhang (2016), "The Economics of Pricing Add-on Products under Duopoly Competition", Twenty-second Americas Conference on Information Systems, San Diego.

Ellison, G. (2005), "A Model of Add-on Pricing", The Quarterly Journal of Economics, Volume 120, Issue 2, 585-637.

Gabaix, X., and Laibson, D. (2006), "Shrouded Attributes, Consumer Myopia, and Information Suppression in Competitive Markets", The Quarterly Journal of Economics, 505-540.

Geng, X., Y. Tan, and L. Wei(2018), "Add-on Pricing and Distribution Contracts", Production and Operations Management, 27(4), 605-623.

Hao, L. and M. Fan (2014), "An analysis of pricing models in the electronic book market", MIS Q, 38(4), 1017-1032.

Hao, L., H. Guo and R. Easley (2016), "A mobile platform's in-app advertising contract under agency pricing for app sales", Production and Operations Management, 26, 189-202.

Lal, R. and C. Matutes (1994), "Retail Pricing and Advertising Strategies", The Journal of Business, Vol. 67, No. 3, 345-370.

Ronayne, D. (2020), "Price Comparison Websites", Warwick Economics Research Paper, No. 1056. 
Shapiro, C. (1995), "Aftermarkets and consumer welfare: Making sense of Kodak", Antitrust Law Journal, 62(2), 484-511.

Shulman, J. D. and X. Geng (2013), "Add-on Pricing by Asymmetric Firms", Management Science, Vol. 59, No. 4, 899-917.

Shulman, J. D. and X. Geng (2016), "Does it pay to Shroud Add-on Fees?", PACIS 2016 Proceedings, 244.

Tian, L., A. Vakharia, Y. Tan and Y. Fan (2017) "Marketplace, reseller, or hybrid: A strategic analysis of an emerging e-commerce model", Production and Operations Management, 27(8), 1595-1610.

Verboven, F. (1999), "Product line rivalry and market segmentation - with an application to automobile optional engine pricing", The Journal of Industrial Economics, 47(4), 399-425.

Wang, C. and J. Wright (2020), Search Platforms: Showrooming and Price Parity Clauses, Rand Journal of Economics, Vol 51 (1), 32-58. 


\section{Appendix}

\section{Proof of Theorem 1}

The sellers' profits are

$$
\begin{array}{r}
\pi_{1}=\gamma\left(\frac{1}{2}+\frac{\alpha_{l}\left(p_{2 L}-p_{1 L}\right)}{2}\right)\left(p_{1 L}-1-k\right)+(1-\gamma) \beta\left(\frac{1}{2}+\frac{\alpha_{s}\left(p_{2 H}-p_{1 H}\right)}{2}\right)\left(p_{1 H}-1-k\right)+ \\
(1-\gamma)(1-\beta)\left(\frac{1}{2}+\frac{\alpha_{n}\left(p_{2 L}-p_{1 L}\right)}{2}\right)\left(p_{1 H}-1-k\right)
\end{array}
$$

and

$$
\begin{aligned}
\pi_{2}=\gamma\left(\frac{1}{2}-\frac{\alpha_{l}\left(p_{2 L}-p_{1 L}\right)}{2}\right) & \left(p_{2 L}-c_{2}-k+x\right)+(1-\gamma) \beta\left(\frac{1}{2}-\frac{\alpha_{s}\left(p_{2 H}-p_{1 H}\right)}{2}\right)\left(p_{2 H}-c_{2}-k+x\right) \\
+ & (1-\gamma)(1-\beta)\left(\frac{1}{2}-\frac{\alpha_{n}\left(p_{2 L}-p_{1 L}\right)}{2}\right)\left(p_{2 H}-c_{2}-k+x\right)
\end{aligned}
$$

Differentiating (8) and (9) with respect to $p_{1 L}, p_{1 H}$ and $p_{2 L}, p_{2 H}$ respectively, and solving for the optimal prices yields

$$
\begin{gathered}
p_{1 L}^{*}=\frac{2(1-\beta)^{3}(1-\gamma)^{2} \alpha_{n}^{3}-\beta(1-\beta)^{2} \gamma(1-\gamma) \alpha_{n}^{2} \alpha_{s}\left(2+\left(1+2 k-x+c_{2}\right) \alpha_{l}\right)}{\beta \gamma \alpha_{s} \alpha_{l}\left(9 \beta \gamma \alpha_{s} \alpha_{l}-2(1-\beta)^{2}(1-\gamma) \alpha_{n}^{2}\right)}+ \\
\frac{3 \beta^{2} \gamma^{2} \alpha_{l} \alpha_{s}^{2}\left(3+\left(2+3 k-x+c_{2}\right) \alpha_{l}\right)+\beta(1-\beta) \gamma(1-\gamma) \alpha_{l} \alpha_{n} \alpha_{s}\left(-9+\beta\left(1+x-c_{2}\right) \alpha_{s}\right)}{\beta \gamma \alpha_{s} \alpha_{l}\left(9 \beta \gamma \alpha_{s} \alpha_{l}-2(1-\beta)^{2}(1-\gamma) \alpha_{n}^{2}\right)} \\
p_{2 L}^{*}=p_{1 L}^{*}-\frac{\beta\left(1+x-c_{2}\right)\left(3 \gamma \alpha_{l}+2(1-\beta)(1-\gamma) \alpha_{n}\right) \alpha_{s}}{9 \beta \gamma \alpha_{l} \alpha_{s}-2(1-\beta)^{2}(1-\gamma) \alpha_{n}^{2}}
\end{gathered}
$$

Similarly,

$$
\begin{gathered}
p_{1 H}^{*}=\frac{-\beta \gamma(1-\beta)\left(1+x-c_{2}\right) \alpha_{n} \alpha_{l} \alpha_{s}-2(1-\beta)^{2}(1-\gamma) \alpha_{n}^{2}\left(1+(1+k) \beta \alpha_{s}\right)}{\beta \alpha_{s}\left(9 \beta \gamma \alpha_{s} \alpha_{l}-2(1-\beta)^{2}(1-\gamma) \alpha_{n}^{2}\right)}+ \\
\frac{3 \beta \gamma \alpha_{l} \alpha_{s}\left(3+\beta \alpha_{s}\left(2+3 k-x+c_{2}\right)\right)}{\beta \alpha_{s}\left(9 \beta \gamma \alpha_{s} \alpha_{l}-2(1-\beta)^{2}(1-\gamma) \alpha_{n}^{2}\right)} \\
p_{2 H}^{*}=p_{1 H}^{*}-\frac{\left(1+x-c_{2}\right)\left(-2(1-\beta)^{2}(1-\gamma) \alpha_{n}^{2}+\gamma \alpha_{l}\left(-2(1-\beta) \alpha_{n}+3 \beta \alpha_{s}\right)\right.}{9 \beta \gamma \alpha_{s} \alpha_{l}-2(1-\beta)^{2}(1-\gamma) \alpha_{n}^{2}}
\end{gathered}
$$


Substituting the above in the platform's payoff:

$$
\begin{aligned}
\pi_{P}=\gamma\left(\frac{1}{2}+\frac{\alpha_{l}\left(p_{2 L}^{*}-p_{1 L}^{*}\right)}{2}\right)+(1-\gamma) \beta\left(\frac{1}{2}+\frac{\alpha_{s}\left(p_{2 H}^{*}-p_{1 H}^{*}\right)}{2}\right)+ \\
(1-\gamma)(1-\beta)\left(\frac{1}{2}+\frac{\alpha_{n}\left(p_{2 L}^{*}-p_{1 L}^{*}\right)}{2}\right)+c_{2} \gamma\left(\frac{1}{2}-\frac{\alpha_{l}\left(p_{2 L}^{*}-p_{1 L}^{*}\right)}{2}\right)+ \\
\quad c_{2}(1-\gamma) \beta\left(\frac{1}{2}-\frac{\alpha_{s}\left(p_{2 H}^{*}-p_{1 H}^{*}\right)}{2}\right)+c_{2}(1-\gamma)(1-\beta)\left(\frac{1}{2}-\frac{\alpha_{n}\left(p_{2 L}^{*}-p_{1 L}^{*}\right)}{2}\right)
\end{aligned}
$$

and maximising with respect to $c_{2}$ yields

$$
\begin{array}{r}
c_{2}^{*}=-\frac{2(1-\beta)^{2}(1-\gamma) \alpha_{n}^{2}-3(2+x)(1-\beta)(1-\gamma) \beta \gamma \alpha_{l} \alpha_{s} \alpha_{n}}{6 \beta \gamma \alpha_{l} \alpha_{s}\left(\gamma \alpha_{l}+(1-\gamma)\left((1-\beta) \alpha_{n}+\beta \alpha_{s}\right)\right)}+ \\
\frac{3 \beta \gamma \alpha_{l} \alpha_{s}\left(3+(2+x) \gamma \alpha_{l}+(2+x) \beta(1-\gamma) \alpha_{s}\right)}{6 \beta \gamma \alpha_{l} \alpha_{s}\left(\gamma \alpha_{l}+(1-\gamma)\left((1-\beta) \alpha_{n}+\beta \alpha_{s}\right)\right)}
\end{array}
$$

Further, substituting for $c_{2}^{*}$ in equations (10), (11), (12) and (13) and differentiating with respect to $\beta$, we get:

$$
\begin{gathered}
\frac{\delta p_{2 L}^{*}}{\delta \beta}=2 \frac{\delta p_{1 L}^{*}}{\delta \beta}=\frac{-(1-\gamma) \alpha_{s}}{\left(\gamma \alpha_{l}+\beta(1-\gamma) \alpha_{s}\right)^{2}}<0 \\
\frac{\delta p_{2 H}^{*}}{\delta \beta}=-\frac{\gamma^{2} \alpha_{l}^{2}+2 \beta(1-\gamma) \gamma \alpha_{l} \alpha_{s}+\beta^{2}\left(2-3 \gamma+\gamma^{2}\right) \alpha_{s}^{2}}{\beta^{2} \alpha_{s}\left(\gamma \alpha_{l}+\beta(1-\gamma) \alpha_{s}\right)^{2}}<0 \\
\frac{\delta p_{1 H}^{*}}{\delta \beta}=\frac{-2 \gamma^{2} \alpha_{l}^{2}-4 \beta(1-\gamma) \gamma \alpha_{l} \alpha_{s}+\beta^{2}\left(-3+5 \gamma-2 \gamma^{2}\right) \alpha_{s}^{2}}{2 \beta^{2} \alpha_{s}\left(\gamma \alpha_{l}+\beta(1-\gamma) \alpha_{s}\right)^{2}}<0 \\
\frac{\delta\left(p_{1 H}^{*}-p_{1 L}^{*}\right)}{\delta \beta}=\frac{\delta\left(p_{2 H}^{*}-p_{2 L}^{*}\right)}{\delta \beta}=\frac{-1}{\beta^{2} \alpha_{s}}<0
\end{gathered}
$$

when $\alpha_{n}$ is close to zero. Thus, the prices of the goods sold by the efficient seller drop by a larger magnitude with increases in the proportion of sophisticated consumers in the population. Similarly,

$$
\frac{\delta p_{2 L}^{*}}{\delta \gamma}=2 \frac{\delta p_{1 L}^{*}}{\delta \gamma}=\frac{-\left(\alpha_{l}-\beta \alpha_{s}\right)}{2\left(\gamma \alpha_{l}+\beta(1-\gamma) \alpha_{s}\right)^{2}}<0
$$

when $\alpha_{n}$ is close to zero, with no change in the price of the add-ons. Note that the assumption of $\alpha_{n}$ close to zero is primarily made for tractability of the analysis. Naive consumers, in general, are relatively price insensitive with more inelastic demands. Though their choice of a seller is based on a comparison of base good prices, the price differential, as such, plays 
a limited role due to their low sensitivity to prices. On the other hand, it has a significant effect on the behaviour of sophisticated consumers or those with very low valuations of quality who are relatively more price sensitive. The assumption of a low $\alpha_{n}$ implies that roughly half the mass of naive consumers visits either store where they are eventually persuaded to purchase add-ons too.

Now, for low type consumers to purchase the base good from, say, the high-cost seller, the following individual rationality and incentive compatibility constraints must hold:

$$
\begin{aligned}
& u-y-\theta-\alpha_{l} p_{1 L}^{*} \geq 0 \\
& u-y-\theta-\alpha_{l} p_{1 L}^{*} \geq u-\theta-\alpha_{l} p_{1 H}^{*} \\
& u-y-\theta-\alpha_{l} p_{1 L}^{*} \geq u-(1-\theta)-\alpha_{l} p_{2 H}^{*}
\end{aligned}
$$

Note that these constraints are satisfied as long as they hold for the consumer, with $\theta=\theta_{l}$, who is indifferent between purchasing from either of the two sellers. Then, substituting for the optimal prices and $\theta_{l}$ in the constraints above, we get

$$
\begin{aligned}
2(u-y)-1 & \geq \alpha_{l}\left(p_{2 L}^{*}+p_{1 L}^{*}\right) \\
y & \leq \alpha_{l}\left(p_{1 H}^{*}-p_{1 L}^{*}\right)=\bar{y}
\end{aligned}
$$

It can be shown that the corresponding constraints for all consumers who buy from the efficient seller are identical to the above and do not place additional restrictions. Similarly, the constraints for the sophisticated consumers are

$$
\begin{aligned}
& u-\theta-\alpha_{s} p_{1 H}^{*} \geq 0 \\
& u-\theta-\alpha_{s} p_{1 H}^{*} \geq u-y-\theta-\alpha_{s} p_{1 L}^{*} \\
& u-\theta-\alpha_{s} p_{1 H}^{*} \geq u-y-(1-\theta)-\alpha_{s} p_{2 L}^{*}
\end{aligned}
$$

which reduce to

$$
\begin{aligned}
2 u-1 & \geq \alpha_{s}\left(p_{1 H}^{*}+p_{2 H}^{*}\right) \\
y & \geq \alpha_{s}\left(p_{2 H}^{*}-p_{2 L}^{*}\right)=\underline{y}
\end{aligned}
$$


upon substitution of the optimal prices and $\theta_{s}$. As before, the corresponding constraints for consumers who buy from the efficient seller do not place additional restrictions. Finally, the relevant constraints for the naive consumers are

$$
\begin{aligned}
u-\theta-\alpha_{n} p_{1 H}^{*} & \geq 0 \\
u-(1-\theta)-\alpha_{n} p_{2 H}^{*} & \geq 0 \\
u-\theta-\alpha_{n} p_{1 H}^{*} & \geq u-y-\theta-\alpha_{n} p_{1 L}^{*} \geq u-y-(1-\theta)-\alpha_{n} p_{2 L}^{*}
\end{aligned}
$$

Upon substitution of the optimal prices and $\theta_{n}$ in the constraints above, the first two individual rationality constraints reduce to

$$
2 u-1 \geq \alpha_{n}\left(2 p_{2 H}^{*}-p_{2 L}^{*}+p_{1 L}^{*}\right)
$$

The left hand side of the last constraint is an incentive compatibility constraints that needs to hold in order for naive consumers to buy add-ons from the high-cost seller at the point of sale. However, it does not place any additional parametric bounds, as it is satisfied as long as the corresponding constraints for the sophisticated consumers hold. This is because both set of consumers purchase the high quality product and the naive consumers are relatively price insensitive in comparison to the sophisticated consumers. Other constraints for consumers buying from the other seller place no additional restrictions.

Then, from equations (16), (17), (18), (19) and (20), $y \in[\underline{y}, \bar{y}]$, while

$$
u \geq \max \left(\frac{1}{2}+\frac{\alpha_{l}\left(p_{2 L}^{*}+p_{1 L}^{*}\right)+2 y}{2}, \frac{1}{2}+\frac{\alpha_{s}\left(p_{2 H}^{*}+p_{1 H}^{*}\right)}{2}, \frac{1}{2}+\frac{\alpha_{n}\left(2 p_{2 H}^{*}-p_{2 L}^{*}+p_{1 L}^{*}\right)}{2}\right)=\bar{u}
$$

Finally, note that decisions made by naive consumers regarding which seller to purchase the high quality bundle from are not necessarily optimal; specifically, there is a mass of consumers who purchase the add-on from the efficient seller but would have been better off buying it from the high-cost seller instead. To see this, note that these consumers choose the efficient seller when

$$
u-y-(1-\theta)-\alpha_{n} p_{2 L}^{*} \geq u-y-\theta-\alpha_{n} p_{1 L}^{*}
$$




$$
\text { or, } \theta \geq \underline{\theta}=\frac{1}{2}+\frac{\alpha_{n}\left(p_{2 L}^{*}-p_{1 L}^{*}\right)}{2}
$$

However, as these consumers buy the add-on too, this decision is optimal ex post only when

$$
\begin{gathered}
u-(1-\theta)-\alpha_{n} p_{2 H}^{*} \geq u-\theta-\alpha_{n} p_{1 H}^{*} \\
\text { or, } \theta \geq \bar{\theta}=\frac{1}{2}+\frac{\alpha_{n}\left(p_{2 H}^{*}-p_{1 H}^{*}\right)}{2}
\end{gathered}
$$

As the efficient seller sells a more expensive add-on, $\underline{\theta}<\bar{\theta}$, so that there is a mass of naive consumers, $(1-\gamma)(1-\beta)(\bar{\theta}-\underline{\theta})$ who buy the bundle from the efficient seller but would have been better off buying from the other seller. Note that the mass of such consumers is decreasing in $c_{2}$, as

$$
(1-\gamma)(1-\beta)(\bar{\theta}-\underline{\theta})=(1-\gamma)(1-\beta) \alpha_{n}\left(p_{2 H}^{*}-p_{2 L}^{*}-\left(p_{1 H}^{*}-p_{1 L}^{*}\right)\right.
$$

and the price of the add-on sold by the high-cost (efficient) seller is increasing (decreasing) in $c_{2}$ :

$$
\frac{\delta\left(p_{2 H}^{*}-p_{2 L}^{*}\right)}{\delta c_{2}}=\frac{-(1-\beta) \alpha_{n}\left(\gamma \alpha_{l}+(1-\gamma)\left((1-\beta) \alpha_{n}+\beta \alpha_{s}\right)\right)}{9 \beta \gamma \alpha_{s} \alpha_{l}-2(1-\beta)^{2}(1-\gamma) \alpha_{n}^{2}}<0=-\frac{\delta\left(p_{1 H}^{*}-p_{1 L}^{*}\right)}{\delta c_{2}}
$$

as long as $\alpha_{l}, \alpha_{s}$ are high enough.

\section{Proof of Theorem 2}

As we find in Theorem 4, $1+x-c_{2}>0$. Then, it is evident from equations (11) and (13) that $p_{1 L}^{*}>p_{2 L}^{*}, p_{1 H}^{*}>p_{2 H}^{*}$, while

$$
p_{1 H}^{*}-p_{1 L}^{*}-\left(p_{2 H}^{*}-p_{2 L}^{*}\right)=\frac{-2(1-\beta)\left(1+x-c_{2}\right) \alpha_{n}\left(\gamma \alpha_{l}+(1-\gamma)\left((1-\beta) \alpha_{n}+\beta \alpha_{s}\right)\right)}{9 \beta \gamma \alpha_{s} \alpha_{l}-2(1-\beta)^{2}(1-\gamma) \alpha_{n}^{2}}<0
$$

as long as $\alpha_{s}, \alpha_{l}$ are high enough, i.e. though the base good sold by the efficient seller is cheaper, it offers a more expensive add-on than the high-cost seller.

However, $\lim _{\beta \rightarrow 0} p_{1 L}^{*}-p_{2 L}^{*}=0$, while $\lim _{\gamma \rightarrow 0} p_{1 L}^{*}-p_{2 L}^{*}=\frac{-\beta \alpha_{s}\left(1+x-c_{2}\right)}{\alpha_{n}(1-\beta)}<0$. Similarly, $\lim _{\beta \rightarrow 0} p_{1 H}^{*}-p_{1 L}^{*}-\left(p_{2 H}^{*}-p_{2 L}^{*}\right)=\frac{\left(1+x-c_{2}\right)\left(\gamma \alpha_{l}+(1-\gamma) \alpha_{n}\right)}{(1-\gamma) \alpha_{n}}>0, \lim _{\gamma \rightarrow 0} p_{1 H}^{*}-p_{1 L}^{*}-\left(p_{2 H}^{*}-p_{2 L}^{*}\right)=$ $\frac{\left(1+x-c_{2}\right)\left(\left(\beta \alpha_{s}+(1-\beta) \alpha_{n}\right)\right.}{(1-\beta) \alpha_{n}}>0$ and $\lim _{\beta \rightarrow 1} p_{1 H}^{*}-p_{1 L}^{*}-\left(p_{2 H}^{*}-p_{2 L}^{*}\right)=0$. 


\section{Proof of Theorem 3}

From equations (10), (11), (12) and (13), we see that when $\alpha_{s}, \alpha_{l}$ are high enough, prices of the base goods are increasing in fees, with the price charged by the efficient seller naturally increasing by a greater extent:

$$
\begin{aligned}
\frac{\delta p_{2 L}^{*}}{\delta c_{2}} & =\frac{-(1-\beta)^{2}(1-\gamma) \alpha_{n}^{2}+6 \beta \gamma \alpha_{s} \alpha_{l}+\beta(1-\beta)(1-\gamma) \alpha_{n} \alpha_{s}}{9 \beta \gamma \alpha_{s} \alpha_{l}-2(1-\beta)^{2}(1-\gamma) \alpha_{n}^{2}}>0 \\
\frac{\delta p_{1 L}^{*}}{\delta c_{2}} & =\frac{-(1-\beta)^{2}(1-\gamma) \alpha_{n}^{2}+3 \beta \gamma \alpha_{s} \alpha_{l}-\beta(1-\beta)(1-\gamma) \alpha_{n} \alpha_{s}}{9 \beta \gamma \alpha_{s} \alpha_{l}-2(1-\beta)^{2}(1-\gamma) \alpha_{n}^{2}}>0
\end{aligned}
$$

Interestingly, the price of the add-on sold by the efficient seller decreases while that sold by the high-cost seller increases (by an equal amount) with increases in fees:

$$
\frac{\delta\left(p_{2 H}^{*}-p_{2 L}^{*}\right)}{\delta c_{2}}=\frac{-(1-\beta) \alpha_{n}\left(\gamma \alpha_{l}+(1-\gamma)\left((1-\beta) \alpha_{n}+\beta \alpha_{s}\right)\right)}{9 \beta \gamma \alpha_{s} \alpha_{l}-2(1-\beta)^{2}(1-\gamma) \alpha_{n}^{2}}<0=-\frac{\delta\left(p_{1 H}^{*}-p_{1 L}^{*}\right)}{\delta c_{2}}
$$

Thus, the efficient seller passes on the higher costs resulting from higher fees through the base good; it lowers the price of its add-on in an attempt to keep the price of its bundle competitive; nevertheless, the price of the high quality bundle increases:

$$
\frac{\delta p_{2 H}^{*}}{\delta c_{2}}=\frac{-2(1-\beta)^{2}(1-\gamma) \alpha_{n}^{2}+\gamma \alpha_{l}\left(6 \beta \alpha_{s}-(1-\beta) \alpha_{n}\right)}{9 \beta \gamma \alpha_{s} \alpha_{l}-2(1-\beta)^{2}(1-\gamma) \alpha_{n}^{2}}>0
$$

as long as $\alpha_{l}, \alpha_{s}$ are high enough. Note that the extent of pass-through is incomplete:

$$
\frac{\delta p_{2 L}^{*}}{\delta c_{2}}-1=\frac{(1-\beta)^{2}(1-\gamma) \alpha_{n}^{2}-3 \beta \gamma \alpha_{s} \alpha_{l}+(1-\beta)(1-\gamma) \beta \alpha_{n} \alpha_{s}}{9 \beta \gamma \alpha_{l} \alpha_{s}-2(1-\beta)^{2}(1-\gamma) \alpha_{n}^{2}}<0
$$

when $\alpha_{s}, \alpha_{l}$ is high enough, i.e. the seller does not pass on the entire increase in its fees. In contrast, any increases in the marginal cost of production are completely passed on to consumers through the base good alone, i.e. $\frac{\delta p_{2 L}^{*}}{\delta k}=1, \frac{\delta p_{1 L}^{*}}{\delta k}=1$, with no pass-through via the add-on.

We now look at how the degree of cost pass-through depends on $\gamma$.

$$
\begin{gathered}
\frac{\delta^{2} p_{2 L}^{*}}{\delta c_{2} \delta \gamma}=\frac{-3(1-\beta) \beta \alpha_{s} \alpha_{n} \alpha_{s}\left((1-\beta) \alpha_{n}+3 \beta \alpha_{s}\right)}{\left(9 \beta \gamma \alpha_{l} \alpha_{s}-2(1-\beta)^{2}(1-\gamma) \alpha_{n}^{2}\right)^{2}}<0 \\
\frac{\delta^{2} p_{2 H}^{*}}{\delta c_{2} \delta \gamma}=\frac{2(1-\beta)^{2} \alpha_{l} \alpha_{n}^{2}\left((1-\beta) \alpha_{n}+3 \beta \alpha_{s}\right)}{\left(9 \beta \gamma \alpha_{l} \alpha_{s}-2(1-\beta)^{2}(1-\gamma) \alpha_{n}^{2}\right)^{2}}>0
\end{gathered}
$$


Similarly, we consider how the pass-through of higher commission fees depends on the fraction of sophisticated consumers, $\beta$ :

$$
\begin{aligned}
\frac{\delta^{2} p_{2 L}^{*}}{\delta c_{2} \delta \beta} & =\frac{(1-\gamma) \alpha_{s} \alpha_{n}\left(-2(1-\beta)^{2}(1-\gamma) \alpha_{n}^{2}-3 \gamma \alpha_{l}\left(\left(1-\beta^{2}\right) \alpha_{n}+3 \beta^{2} \alpha_{s}\right)\right)}{\left(9 \beta \gamma \alpha_{l} \alpha_{s}-2(1-\beta)^{2}(1-\gamma) \alpha_{n}^{2}\right)^{2}}<0 \\
\frac{\delta^{2} p_{2 H}^{*}}{\delta c_{2} \delta \beta} & =\frac{\gamma \alpha_{l} \alpha_{s}\left(2(1-\beta)^{2}(1-\gamma) \alpha_{n}^{2}+9 \gamma \alpha_{l} \alpha_{s}+6\left(1-\beta^{2}\right)(1-\gamma) \alpha_{n} \alpha_{s}\right)}{\left(9 \beta \gamma \alpha_{l} \alpha_{s}-2(1-\beta)^{2}(1-\gamma) \alpha_{n}^{2}\right)^{2}}>0
\end{aligned}
$$

Thus, the increase in the price of the base good sold by the efficient seller owing to increases in commission fees is lower when there is a greater mass of sophisticated consumers or low type consumers. At the same time, the decrease in the price of the add-on with increases in commission fees is also lower.

In the limiting case, when there are no naive consumers in the population, i.e. $\beta=1$, the price of the base good sold by the efficient seller increases:

$$
\frac{\delta p_{2 H}^{*}}{\delta c_{2}}=\frac{2}{3}
$$

There is no change in the price of its add-on.

Conversely, when $\beta=0$, i.e. all consumers with a high valuation of quality are naive,

$$
\frac{\delta p_{2 L}^{*}}{\delta c_{2}}=\frac{1}{2}
$$

The price of its add-on increases too:

$$
\frac{\delta\left(p_{2 H}^{*}-p_{2 L}^{*}\right)}{\delta c_{2}}=\frac{\gamma \alpha_{l}+(1-\gamma) \alpha_{n}}{2(1-\gamma) \alpha_{n}}>0
$$

\section{Proof of Theorem 4}

The platform charges a higher commission fee from the efficient seller:

$$
\begin{aligned}
c_{2}^{*}-1=\frac{-2(1-\beta)^{2}(1-\gamma) \alpha_{n}^{2}+3 x \beta \gamma(1-\beta)(1-\gamma) \alpha_{n} \alpha_{s} \alpha_{l}}{6 \beta \gamma \alpha_{l} \alpha_{s}\left(\gamma \alpha_{l}+(1-\gamma)\left((1-\beta) \alpha_{n}+\beta \alpha_{s}\right)\right.} & \\
& +\frac{3 \beta \gamma \alpha_{l} \alpha_{s}\left(3+x \gamma \alpha_{l}+x \beta(1-\gamma) \alpha_{s}\right)}{6 \beta \gamma \alpha_{l} \alpha_{s}\left(\gamma \alpha_{l}+(1-\gamma)\left((1-\beta) \alpha_{n}+\beta \alpha_{s}\right)\right.}>0
\end{aligned}
$$


but, despite a higher fee, the total cost differential:

$$
\begin{aligned}
& 1+x-c_{2}^{*}=\frac{2(1-\beta)^{2}(1-\gamma) \alpha_{n}^{2}+3 x \beta \gamma(1-\beta)(1-\gamma) \alpha_{n} \alpha_{s} \alpha_{l}}{6 \beta \gamma \alpha_{l} \alpha_{s}\left(\gamma \alpha_{l}+(1-\gamma)\left((1-\beta) \alpha_{n}+\beta \alpha_{s}\right)\right.} \\
& -\frac{3 \beta \gamma \alpha_{l} \alpha_{s}\left(3-x \gamma \alpha_{l}-x \beta(1-\gamma) \alpha_{s}\right)}{6 \beta \gamma \alpha_{l} \alpha_{s}\left(\gamma \alpha_{l}+(1-\gamma)\left((1-\beta) \alpha_{n}+\beta \alpha_{s}\right)\right.}>0
\end{aligned}
$$

remains in favour of the more efficient firm as long as $\alpha_{s}, \alpha_{l}$ are high enough.

Next, consider the impact of an increase in the number of sophisticated consumers in the population, $\beta$, on the platform's revenues. When $\alpha_{n}$ is close to zero and $\alpha_{s}, \alpha_{l}$ are high enough,

$$
\frac{\delta \pi_{P}}{\delta \beta}=\frac{(1-\gamma) \alpha_{s}\left(-9+x^{2} \gamma^{2} \alpha_{l}^{2}+2 x^{2} \beta \gamma(1-\gamma) \alpha_{l} \alpha_{s}+x^{2} \beta^{2}(1-\gamma)^{2} \alpha_{s}^{2}\right)}{24\left(\gamma \alpha_{l}+\beta(1-\gamma) \alpha_{s}\right)^{2}}>0
$$

while commission fees are decreasing in $\beta$ :

$$
\frac{\delta c_{2}^{*}}{\delta \beta}=\frac{-3(1-\gamma) \alpha_{s}}{2\left(\gamma \alpha_{l}+\beta(1-\gamma) \alpha_{s}\right)^{2}}<0
$$

Similarly, an increase in $\gamma$ leads to a drop in fees:

$$
\frac{\delta c_{2}^{*}}{\delta \gamma}=\frac{-3\left(\alpha_{l}-\beta \alpha_{s}\right)}{2\left(\gamma \alpha_{l}+\beta(1-\gamma) \alpha_{s}\right)^{2}}<0
$$

and an increase in revenues:

$$
\frac{\delta \pi_{P}}{\delta \gamma}=\frac{\left(\alpha_{l}-\beta \alpha_{s}\right)\left(-9+x^{2} \gamma^{2} \alpha_{l}^{2}+2 x^{2} \beta \gamma(1-\gamma) \alpha_{l} \alpha_{s}+x^{2} \beta^{2}(1-\gamma)^{2} \alpha_{s}^{2}\right)}{24\left(\gamma \alpha_{l}+\beta(1-\gamma) \alpha_{s}\right)^{2}}>0
$$

Increases in the cost advantage, $x$, have a positive impact on platform's revenues and fees when $\alpha_{s}, \alpha_{l}$ are high enough:

$$
\begin{gathered}
\frac{\delta \pi_{P}}{\delta x}=\frac{-2(1-\beta)^{2}(1-\gamma) \alpha_{n}^{2}+3 x \beta \gamma(1-\beta)(1-\gamma) \alpha_{n} \alpha_{s} \alpha_{l}}{4\left(9 \beta \gamma \alpha_{l} \alpha_{s}-2(1-\gamma)(1-\beta)^{2} \alpha_{n}^{2}\right)} \\
+\frac{3 \beta \alpha_{s} \alpha_{l} \gamma\left(3+x \gamma \alpha_{l}+x \beta(1-\gamma) \alpha_{s}\right)}{4\left(9 \beta \gamma \alpha_{l} \alpha_{s}-2(1-\gamma)(1-\beta)^{2} \alpha_{n}^{2}\right)}>0 \\
\frac{\delta c_{2}^{*}}{\delta x}=\frac{1}{2}>0
\end{gathered}
$$

Finally, consider the impact of an increase in the price sensitivity of naive consumers, $\alpha_{n}$, 
on the platform's revenues and commission fees:

$$
\frac{\delta \pi_{P}}{\delta \alpha_{n}}=t_{1} \cdot\left[t_{2}+t_{3}+t_{4}\right]
$$

where

$$
\begin{aligned}
t_{1} & =\frac{(1-\beta)(1-\gamma)\left(2(1-\beta)(1-\gamma) \alpha_{n}\left((1-\beta) \alpha_{n}+2 \beta \alpha_{s}\right)+\gamma \alpha_{l}\left(4(1-\beta) \alpha_{n}+9 \beta \alpha_{s}\right)\right)}{6 \beta \gamma \alpha_{l} \alpha_{s}\left(-4(1-\beta)^{2}(1-\gamma) \alpha_{n}^{2}+18 \beta \gamma \alpha_{l} \alpha_{s}\right)^{2}\left(\gamma \alpha_{l}+(1-\gamma)\left((1-\beta) \alpha_{n}+\beta \alpha_{s}\right)\right)^{2}}>0 \\
t_{2} & =\frac{-4(1-\beta)^{4}(1-\gamma)^{2} \alpha_{n}^{4}+18 x^{2}(1-\beta) \beta^{2}(1-\gamma) \gamma^{2} \alpha_{l}^{2} \alpha_{n} \alpha_{s}^{2}\left(\gamma \alpha_{l}+\beta(1-\gamma) \alpha_{s}\right)}{6 \beta \gamma \alpha_{l} \alpha_{s}\left(-4(1-\beta)^{2}(1-\gamma) \alpha_{n}^{2}+18 \beta \gamma \alpha_{l} \alpha_{s}\right)^{2}\left(\gamma \alpha_{l}+(1-\gamma)\left((1-\beta) \alpha_{n}+\beta \alpha_{s}\right)\right)^{2}}>0 \\
t_{3}= & \frac{9(1-\beta)^{2} \beta(1-\gamma) \gamma \alpha_{l} \alpha_{s} \alpha_{n}^{2}\left(4+x^{2} \beta(1-\gamma) \gamma \alpha_{l} \alpha_{s}\right)}{6 \beta \gamma \alpha_{l} \alpha_{s}\left(-4(1-\beta)^{2}(1-\gamma) \alpha_{n}^{2}+18 \beta \gamma \alpha_{l} \alpha_{s}\right)^{2}\left(\gamma \alpha_{l}+(1-\gamma)\left((1-\beta) \alpha_{n}+\beta \alpha_{s}\right)\right)^{2}}>0 \\
t_{4}= & \frac{9 \beta^{2} \gamma^{2} \alpha_{l}^{2} \alpha_{s}^{2}\left(-9+x^{2} \gamma^{2} \alpha_{l}^{2}+2 x^{2} \beta(1-\gamma) \gamma \alpha_{l} \alpha_{s}+x^{2} \beta^{2}(1-\gamma)^{2} \alpha_{s}^{2}\right)}{6 \beta \gamma \alpha_{l} \alpha_{s}\left(-4(1-\beta)^{2}(1-\gamma) \alpha_{n}^{2}+18 \beta \gamma \alpha_{l} \alpha_{s}\right)^{2}\left(\gamma \alpha_{l}+(1-\gamma)\left((1-\beta) \alpha_{n}+\beta \alpha_{s}\right)\right)^{2}}>0
\end{aligned}
$$

when $\alpha_{s}, \alpha_{l}$ are high enough. Similarly,

$$
\frac{\delta c_{2}}{\delta \alpha_{n}}=\frac{(1-\beta)(1-\gamma)\left[-\gamma \alpha_{l}\left(4(1-\beta) \alpha_{n}+9 \beta \alpha_{s}\right)-2(1-\beta)(1-\gamma) \alpha_{n}\left((1-\beta) \alpha_{n}+2 \beta \alpha_{s}\right)\right]}{6 \beta \gamma \alpha_{l} \alpha_{s}\left(\gamma \alpha_{l}+(1-\gamma)\left((1-\beta) \alpha_{n}+\beta \alpha_{s}\right)\right)^{2}}<0
$$

Thus, the platform's revenues are increasing and the fees charged are decreasing in the price sensitivity of the naive consumers. 